\title{
Odontogenic Myxoma - A Case Report and Review of Literature
}

\author{
Divya Sanjeevi Ramakrishnan ${ }^{1}$, Sudarssan Subramaniam Gouthaman², Senthilnathan Periasamy ${ }^{3}$ \\ ${ }^{1,2,3}$ Department of Oral Surgery, Saveetha Institute of Medical and Technical Sciences, Chennai, Tamil Nadu, India.
}

\section{INTRODUCTION}

Myxomas are slow-growing, locally aggressive benign mesenchymal neoplasms commonly found in skin, subcutaneous tissue and the heart (left atrium), but rarely in the head and neck region. ${ }^{1}$ Odontogenic myxoma (OM) of the jaws was described by Goldman and Thoma in 1947. Odontogenic myxoma is an intraosseous neoplasm arising from odontogenic ectomesenchyme of developing enamel organ. ${ }^{2}$ These cells are dispersed in loose myxoid stroma with variable collagen content. ${ }^{3,4}$ As these tumours are non-encapsulated, infiltration into surrounding medullary bone seemed to be readily accessible. Accounting for this very reason, recurrence rate accounts to $1-19 \%$ of all odontogenic tumours. ${ }^{5}$ Recurrence rate is unclear as lack of explicit reports and follow up of them.

Odontogenic myxoma is customarily treated by surgical excision; however, there exists controversy regarding the most appropriate treatment modality. In view of its rarity, diagnostic and operative dilemma encountered while managing, the present case is here with reports on the clinical features, differential diagnosis, and management strategies of odontogenic myxoma.

It is the third most common odontogenic tumour with slight predilection in females. The mandible is more commonly involved than the maxilla and usually seen in the $2^{\text {nd }}$ or $3^{\text {rd }}$ decade of age. It is often asymptomatic and presents as a painless swelling. Radiographic features are variable features such as unilocular or multilocular radiolucency with honeycomb, soap bubble or tennis racket pattern with cortical plate expansion. A case of odontogenic myxoma in a 33 year old female patient involving the right maxilla extensively within a span of 6 months is reported. Such rapid, extensive growths are very few in literature, and hence, make this case one of the rare cases. The patient was treated with right subtotal maxillectomy. The patient is presently under follow-up.

\section{PRESENTATION OF CASE}

A 33-year-old female patient reported to the Department of Oral \& Maxillofacial Surgery with pain and swelling of the right cheek region which increased rapidly to its current size over the past 6 months. On extra oral examination, the swelling was mild [Figure 10]. The swelling was firm and nontender without change in skin colour. Patients also complained of paraesthesia in the right infraorbital region. Right nasal block was noted. The patient's medical and dental history was non-contributory. Intra-oral examination revealed obliteration of upper right buccal vestibule.

Orthopantomogram (OPG) of the patient showed features of diffused multilocular radiolucency involving the right maxillary alveolus and CT image showed large expansile mass in the right maxilla with complete obliteration of the right maxillary sinus [Figure 1]. Resorption of roots was evident in 14, 15 and missing 16 - which was extracted 6 years ago due to gross decay and which was unrestorable. The radiolucency measured $5 \mathrm{~cm} \times 3 \mathrm{~cm}$.
Corresponding Author: Divya Sanjeevi Ramakrishnan. B1,143 Kendhriya Vihar Apartments, Velapanchavadi, Chennai-600077, Tamil Nadu, India.

E-mail: divyaramakrishnan55@gmail.com

DOI: $10.14260 / j e m d s / 2020 / 731$

How to Cite This Article:

Ramakrishnan DS, Gouthaman SS, Periasamy S. Odontogenic myxoma - a case report and review of literature. J Evolution Med Dent Sci 2020;9(44):3331-3334, DOI: 10.14260/jemds/2020/731

Submission 06-07-2020,

Peer Review24-09-2020,

Acceptance 30-09-2020,

Published 02-11-2020.

Copyright (C) 2020 Divya Sanjeevi Ramakrishnan et al. This is an open access article distributed under Creative Commons Attribution License [Attribution 4.0 International (CC BY 4.0)] 

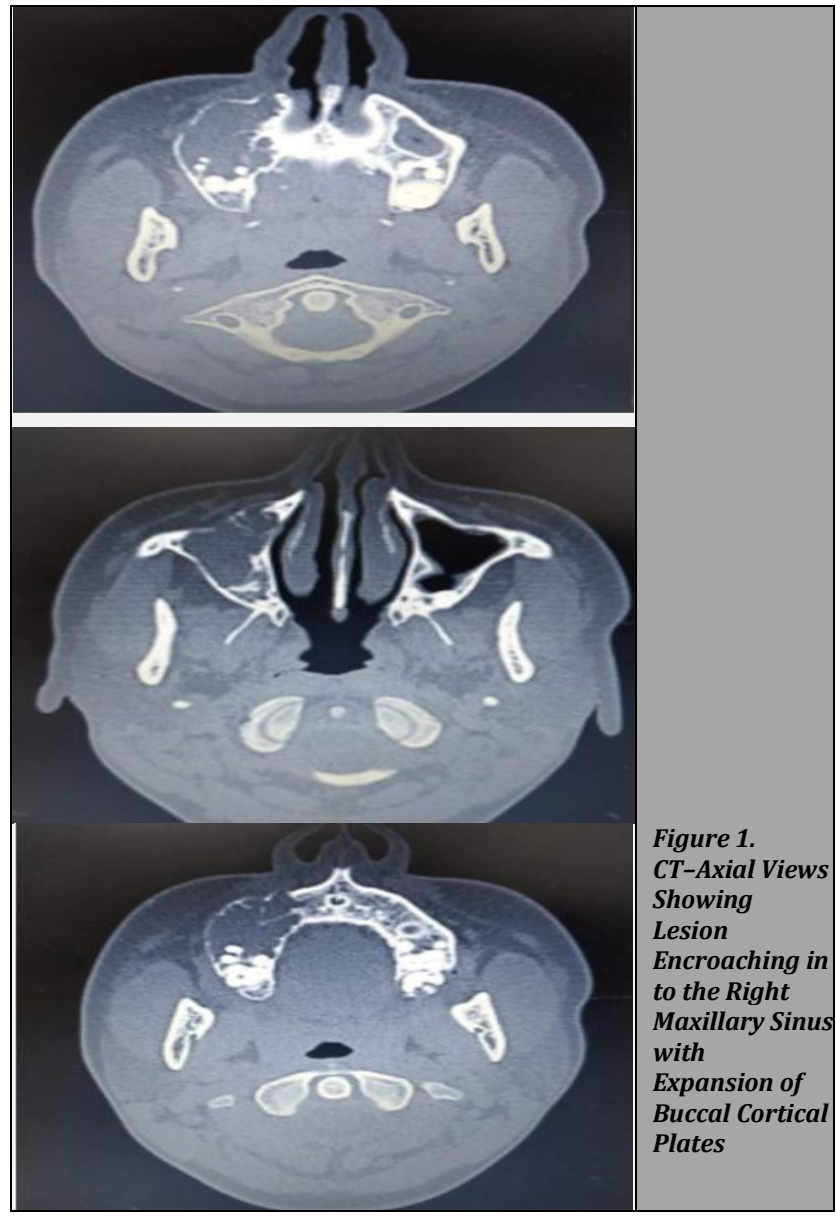

Incisional biopsy was conclusive of odontogenic myxoma of right maxilla. The lesion was removed in toto along with teeth through intra oral incision and high maxillary osteotomy cut was placed, the alveolar arch, part of hard palate and maxilla was removed. After in toto resection of the lesion, the peripheral osteotomy was done all over the margins of the cavity to prevent recurrence (Figure $2 \mathrm{a}, \mathrm{b}$ ). The buccal pad of fat is released, extended to cover the defect and primary closure was achieved (Figure 2 c, d). Immediately following surgery, surgical obturator was provided to patient. After 5 days of hospitalisation the patient was discharged. The postoperative course of healing was uneventful. The patient is followed up post operatively 9 months without any radiological recurrence. The resected segment [Figure 3] was sent for histopathological examination and it was confirmed as odontogenic myxoma of maxillary sinus. On gross examination, it appears as a nodular mass of heterogeneous slimy tissue. On histopathological examination, the spindleshaped cells arranged loosely in myxoid stroma. Blood vessels and collagen fibers were sparse.

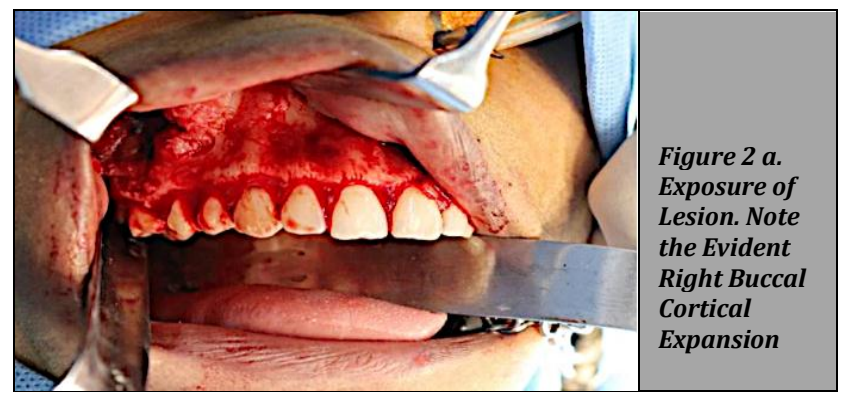

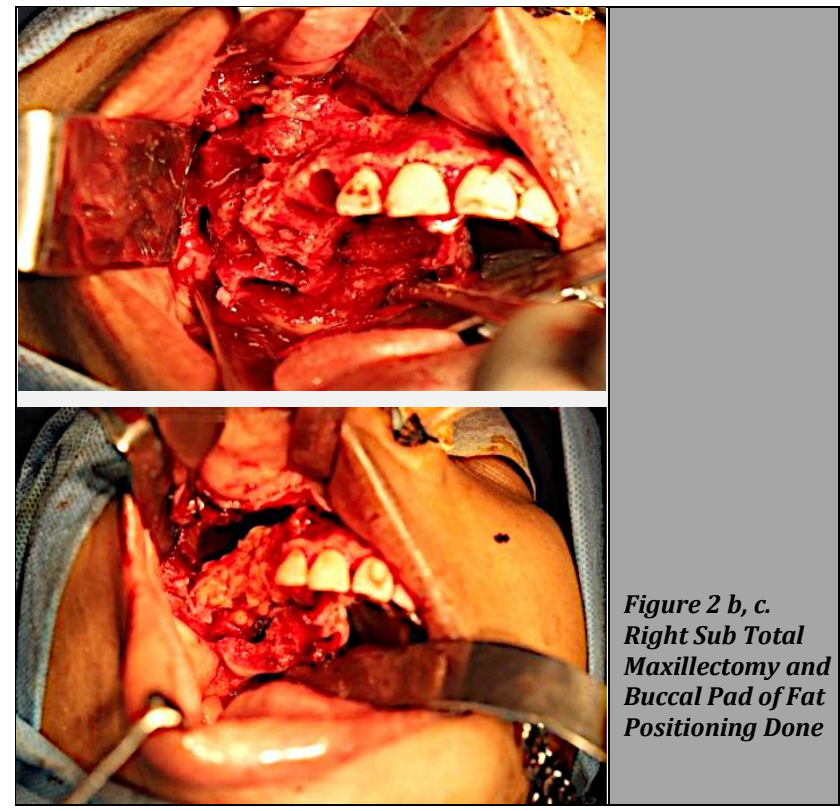
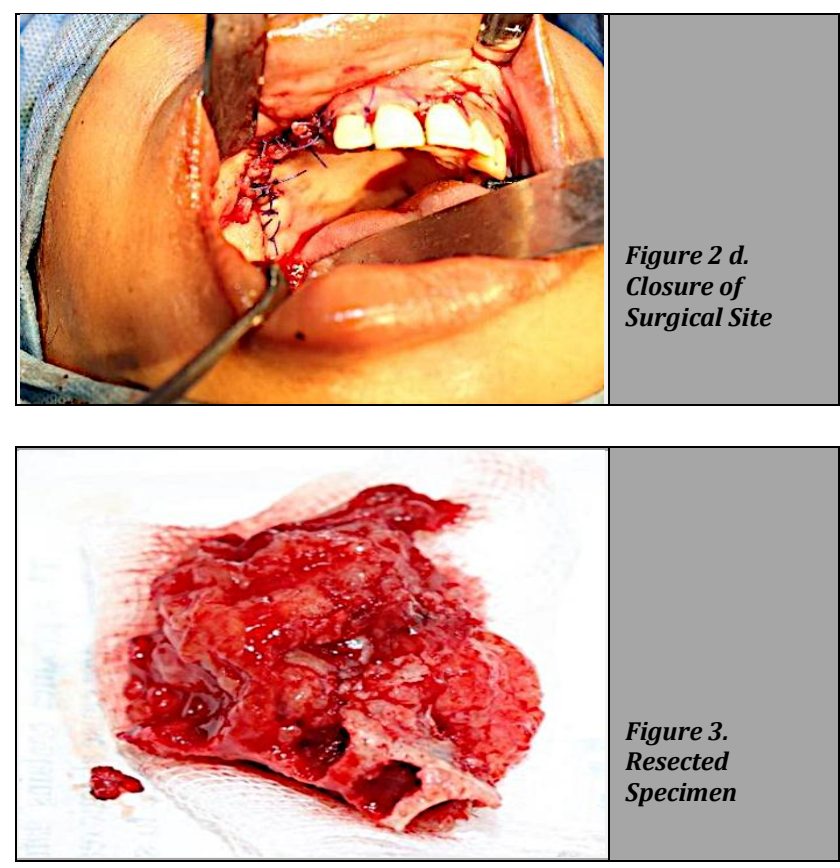

\section{DISCUSSION}

Jaw bones are the common site for myxomas; whereas, pharynx, larynx, paranasal sinuses and other soft tissues are rarely affected. 6 It accounts for $3-6 \%$ of all odontogenic tumours.7,8 It is a slow-growing neoplasm, infiltrative in growth and aggressive in nature with high recurrence rate..$^{9,10}$ Female predilection and mandible is the most common site than maxilla. ${ }^{11}$

The posterior region is the common site for maxilla. ${ }^{12}$ They are usually detected during routine examinations as being asymptomatic. The symptoms are swelling, heaviness and sometimes with mobility of the teeth. In our report the patient was asymptomatic before 5 months, the swelling was associated with mobility of $14,15,16$. Usually the entire maxillary antrum is involved with nasal blockage and exophthalmos are the prominent signs. ${ }^{13}$ 
Classification of odontogenic myxoma by Zhang et al. describes the various radiographic appearances. Type I is a unilocular radiolucency. Type II is multilocular radiolucencies creating a "honeycomb", "soap bubble", or "tennis racket" appearance. Type III includes lesions that involve local alveolar bone. Type IV lesions are of those involving the maxillary sinus. Lesions that cause osteolytic destruction and "moth-eaten" margins are categorized as type V. Lastly, the sunray appearance is classified as type VI.14

Histologically the WHO (1992) defined OM as "A locally invasive neoplasm consisting of rounded and angular cells lying in an abundant myxoid stroma." 15 They show loose myxoid stroma containing spindle-stellate and angular or round cells. Stroma shows very few fine fibrillar material with minimum vascularity. Calcifications may or may not be present. Inflammatory infiltration predominantly of lymphocytes and remnants of odontogenic epithelium are seen. In our case the histological features were similar to that of the literature. Epithelial islands are not commonly observed in the myxomas of jaws. The mucoid nature of $\mathrm{OM}$ was confirmed with positive reaction with Alcian blue and negative reaction with PAS stain. ${ }^{16}$

The appropriate treatment course would follow and consider characteristics of tumour based on clinical behaviour, location, size, type, recurrence rate and patient factors such as age, sex and comorbidities. Odontogenic myxoma were treated by conservative surgical modality (45.5\%) and others by radical treatment. With data from various studies, it's been proved that $\mathrm{OM}$ is radio resistant. ${ }^{17}$ The overall mean followup period in literature is 46.4 months and no recurrences were noted with radical treatment. However, the rate of recurrence following conservative surgery is $(10-30 \%)$ higher than that of radical as the odontogenic myxoma is non encapsulated and infiltrative thereby and also without any subsequent destruction. ${ }^{18}$ thus the complete removal of the lesion is challenging with conservative approach and may be the reason behind high recurrence rate. ${ }^{19,20}$ Incomplete removal of tumour leads to recurrence, rather than the intrinsic biological behaviour of the tumour. The recommended protocol would be close follow up of these patients at least for a minimum period of 2 years.

\section{CONCLUSIONS}

Odontogenic myxoma is a slow growing benign, locally invasive tumour, known for high recurrence. Due to its variant clinical and radiological features, it should be considered in differential diagnosis of both radiolucent and radiopaque lesions in both jaws. A sound knowledge with proper histopathological diagnosis is required for efficient management of such lesions.

With appropriate treatment, the prognosis of odontogenic myxoma is good and long term follow-up of cases is necessary, specifically those treated with a more conservative approach. Seldom, initial clinicoradiological diagnosis followed by corresponding histopathological report helps in arriving at an appropriate diagnosis and aids in constructing a treatment modality with minimal recurrences. Currently, we lack data on the number of reported cases of $\mathrm{OM}$ in Indian population; in addition there is a deficiency of information regarding recurrence rates in OMs, especially concerning different surgical approaches.

Financial or other competing interests: None.

Disclosure forms provided by the authors are available with the full text of this article at jemds.com.

The authors certify that they have obtained all appropriate patient consent forms and due efforts will be made to conceal their identity.

\section{REFERENCES}

[1] Munjal M, Bhardwaj V, Garg B, et al. Odontogenic myxoma of the maxilla: a clinical case report and review of literature. Online J Otolaryngology 2013;3(2):51-60.

[2] White SC, Pharoah MJ. Oral Radiology - E-Book: principles and Interpretation. Elsevier Health Sciences 2014: p. 696.

[3] Neville BW, Damm DD, Allen C, et al. Oral and maxillofacial pathology. $4^{\text {th }}$ edn. Elsevier Health Sciences 2015: p. 928.

[4] de Melo AUC, de Farias Martorelli SB, de Holanda Cavalcanti $\mathrm{PH}$, et al. Maxillary odontogenic myxoma involving the maxillary sinus - case report. Rev Bras Otorrinolaringol 2008;74(3):472-5.

[5] Simon ENM, Merkx MAW, Vuhahula E, et al. Odontogenic myxoma: a clinicopathological study of 33 cases. Int J Oral Maxillofac Surg 2004;33(4):333-7.

[6] Moore BA, Wine T, Burkey BB, et al. Sphenoid sinus myxoma: case report and literature review. Ochsner J 2008;8(4):166-71.

[7] Sumi Y, Miyaishi O, Ito K, et al. Magnetic resonance imaging of myxoma in the mandible: a case report. Oral Surg Oral Med Oral Pathol Oral Radiol Endod 2000;90(5):671-6.

[8] Boffano P, Gallesio C, Barreca A, et al. Surgical treatment of odontogenic myxoma. J Craniofac Surg 2011;22(3):982-7.

[9] Kiresur MA, Hemavathy S. An aggressive odontogenic myxoma of the maxilla. Indian J Dent 2014;5(4):214-7.

[10] Gupta S, Grover N, Kadam A, et al. Odontogenic myxoma. Natl J Maxillofac Surg 2013;4(1):81-3.

[11] Rani V, Kadar MKM, Babu A, et al. Odontogenic myxoma diagnostic dilemma: a case report and review of literature. J Cranio-Maxillary Dis 2014;3(2):163-7.

[12] Noffke CEE, Raubenheimer EJ, Chabikuli NJ, et al. Odontogenic myxoma: review of the literature and report of 30 cases from South Africa. Oral Surg Oral Med Oral Pathol Oral Radiol Endod 2007;104(1):101-9.

[13] Kaffe I, Naor H, Buchner A. Clinical and radiological features of odontogenic myxoma of the jaws. Dentomaxillofac Radiol 1997;26(5):299-303.

[14] Zhang J, Wang H, He X, et al. Radiographic examination of 41 cases of odontogenic myxomas on the basis of conventional radiographs. Dentomaxillofac Radiol 2007;36(3):160-7.

[15] Reichart PA, Philipsen HP. Odontogenic tumors and allied lesions. Quintessence Publishing Co., Ltd 2004: p. 387.

[16] Kim S. Bancroft's theory and practice of histological techniques. $7^{\text {th }}$ edn. Churchill Livingstone 2012.

[17] Landa LE, Hedrick MH, Nepomuceno-Perez MC, et al. Recurrent myxoma of the zygoma: a case report. J Oral Maxillofac Surg 2002;60(6):704-8. 
[18] Rocha AC, Gaujac C, Ceccheti MM, et al. Treatment of recurrent mandibular myxoma by curettage and cryotherapy after thirty years. Clinics 2009;64(2):149-52.

[19] Muzio LL, Nocini P, Favia G, et al. Odontogenic myxoma of the jaws: a clinical, radiologic, immunohistochemical, and ultrastructural study. Oral Surg Oral Med Oral Pathol Oral Radiol Endod 1996;82(4):426-33.

[20] Leiser Y, Abu-El-Naaj I, Peled M. Odontogenic myxoma--a case series and review of the surgical management. J Craniomaxillofac Surg 2009;37(4):206-9. 